\title{
A convergent rhodium-catalysed asymmetric synthesis of tetrahydroquinolines $\dagger$
}

Cite this: Chem. Commun., 2014, 50, 10222

Received 27th June 2014, Accepted 18th July 2014

DOI: $10.1039 / c 4 c c 04940 c$

www.rsc.org/chemcomm

\author{
Ho Yin Li, ${ }^{a}$ Joachim Horn, ${ }^{a}$ Amanda Campbell, ${ }^{b}$ David House, ${ }^{b}$ Adam Nelson ${ }^{\text {ac }}$ \\ and Stephen P. Marsden*a
}

Rh-catalysed conjugate additions of 2-aminophenyl boronic acid derivatives were exploited in diastereoselective and asymmetric syntheses of tetrahydroquinolines. In both cases, combinatorial variation of the substitution of the tetrahydroquinoline ring system was possible.

The tetrahydroquinoline ring system is an important synthetic target ${ }^{1}$ that is found in many bioactive compounds including natural products (e.g. dynemicin $\mathrm{A}^{2}$ ) and drugs (e.g. the thrombin inhibitor $\operatorname{argatroban}^{3 a} \mathbf{1}$ and the antiarrhythmic agent nicainoprol ${ }^{3 b} 2$ ). Established catalytic asymmetric synthetic approaches to tetrahydroquinolines include transition metal-catalysed hydrogenation and transfer-hydrogenation of quinolines, ${ }^{4}$ organocatalytic reduction of quinolines ${ }^{5}$ and dihydroquinolines, ${ }^{6}$ hetero-Diels-Alder reactions of aniline-derived imines with electron-rich dienophiles (Povarov reactions) $^{7}$ and catalysed intramolecular hydride transfer/ Mannich condensations. ${ }^{8}$<smiles>CC1CCN(C(=O)[C@H](CCCN=C(N)N)NS(=O)(=O)c2cccc3c2NC[C@H](C)C3)[C@H](C(=O)O)C1</smiles><smiles>CCCNCC(O)COc1cccc2c1N(C(=O)c1cccnc1)CCC2</smiles>

As part of a programme focused on the synthesis of diverse small molecule scaffolds, ${ }^{9}$ we have exploited Rh-catalysed conjugate additions ${ }^{10}$ in convergent heterocycle syntheses. ${ }^{9 a, b}$ For example, Rh-catalysed conjugate addition of 2-aminophenyl boronic acids 3 to enones $\mathbf{4}$ was followed by cyclisation $¥(\rightarrow \mathbf{5})$ and oxidation to give quinolines 6 in good yield (Scheme 1). ${ }^{9 a}$

\footnotetext{
${ }^{a}$ School of Chemistry, University of Leeds, Leeds, LS2 9JT, UK.

E-mail: a.s.nelson@leeds.ac.uk,s.p.marsden@leeds.ac.uk

${ }^{b}$ GlaxoSmithKline Medicines Research Centre, Stevenage, SG1 2NY, UK

${ }^{c}$ Astbury Centre for Structural Molecular Biology, University of Leeds, Leeds, LS2 9JT, UK

$\dagger$ Electronic supplementary information (ESI) available. See DOI: 10.1039/ c4cc04940c
}

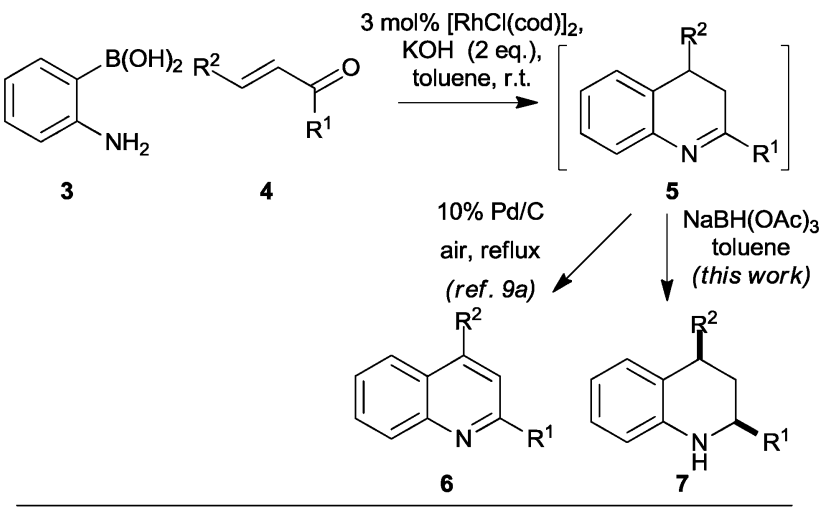<smiles>CCCCCCC1CC(C)Nc2ccccc21</smiles>

7a, $94 \%$, dr $88: 12$<smiles>CC1CC(C)c2ccccc2N1</smiles>

7d, $54 \%, d r 88: 12$<smiles>c1ccc(C2CCc3ccccc3N2)cc1</smiles>

$7 b, 33 \%$<smiles>C[C@@H]1CC(Br)c2ccccc2N1</smiles>

7e, $91 \%, d r 88: 12$<smiles>c1ccc([C@H]2C[C@H](c3ccccc3)c3ccccc3N2)cc1</smiles>

$7 c, 96 \%, d r>95:<5$<smiles>Cn1cccc1[C@@H]1C[C@H]([Al])c2ccccc2N1</smiles>

7f, $80 \%, d r>95:<5$
Scheme 1 Stereoselective synthesis of tetrahydroquinolines. Diastereomeric ratios $(\mathrm{dr})$ are reported for the purified products. Ar $=p$-methoxyphenyl; $\mathrm{Ar}^{\prime}=p$-nitrophenyl.

The reaction presumably proceeds by intramolecular condensation of the initial conjugate addition adduct to yield a 3,4-dihydroquinoline 5 and, hence, the corresponding quinoline 6.

Although the general approach might, in principle, be exploited in asymmetric heterocycle synthesis, it had only been demonstrated in the synthesis of achiral ${ }^{9 a, b}$ or racemic ${ }^{9 b}$ heterocycles. We recognized that Rh-catalysed conjugate addition chemistry might enable a new convergent, and potentially asymmetric, ${ }^{11}$ synthesis of substituted tetrahydroquinolines 7 (Scheme 1). Initial studies focused on 
the convergent synthesis of the racemic tetrahydroquinoline 7a. Thus, after completion of the Rh-catalysed conjugate addition reaction, the reaction mixture was diluted with toluene and treated with an excess of sodium triacetoxyborohydride: the tetrahydroquinoline 7a was obtained in 94\% yield with 88:12 diastereoselectivity.

Our initial studies into the scope of the convergent synthesis of racemic tetrahydroquinolines 7 are summarised in Scheme 1. The synthesis of the 2-substituted tetrahydroquinoline $7 \mathbf{b}$ was lower yielding that that of the 2,4-disubstituted analogue 7a. However, with all of the $\alpha, \beta$-disubstituted enones 4 studied, the reaction yielded the corresponding 2,4-disubstituted tetrahydroquinolines 7c-f in reasonable to excellent yield with both aliphatic and aromatic $\mathrm{R}^{1}$ and $\mathrm{R}^{2}$ substituents. In each case, the products were obtained with good to excellent diastereoselectivity in favour of the cis isomer.

To enable substitution of the benzenoid ring, we investigated the use of 2-aminophenylpinacolboronates $\mathbf{8}$, which may be prepared easily from the corresponding 2-bromoanilines (Scheme 2). ${ }^{12}$ The reaction between the parent pinacolboronate $8\left(\mathrm{R}^{3}=\mathrm{H}\right)$ with chalcone was slower than that of the corresponding boronic acid 3 . However, by increasing the catalyst loading (to $6 \mathrm{~mol} \%$ ), and the amount of base (to 2.5 eq.), the reaction was complete in a similar time, and a comparable yield of the tetrahydroquinoline $7 \mathbf{c}$ was obtained (compare Scheme 1 with Scheme 2). Remarkably, the synthesis of the 2-substituted tetrahydroquinoline $\mathbf{7 b}$ was much more effective with the pinacolboronate $8\left(\mathrm{R}^{3}=\mathrm{H}\right)$ as the reactant, and a much improved $77 \%$ yield was observed (compare Scheme 1 with Scheme 2). In a similar vein, the 2,4 -disubstituted tetrahydroquinolines $7 \mathbf{g}-\mathbf{i}$
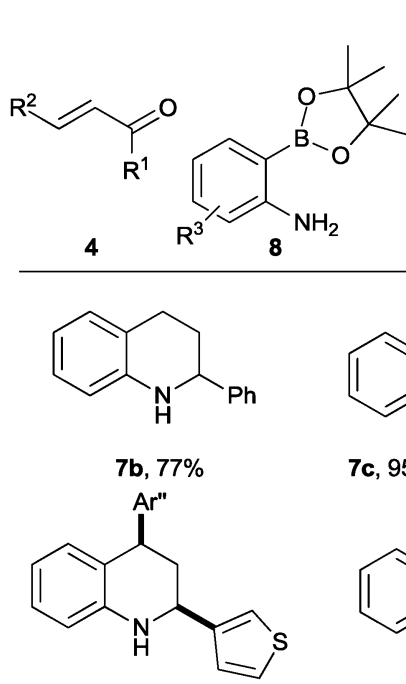

7h, $81 \%, d r>95:<5$<smiles>[R]C1C[C@H]([Z15])c2ccc(C(F)(F)F)cc2N1</smiles>

$7 \mathbf{k}\left(\mathbf{R}^{1}=\mathrm{Me}\right), 73 \%, d r$ 90:10 $7 \mathrm{I}\left(\mathrm{R}^{1}=\mathrm{Ph}\right), 81 \%, d r$ 95:5
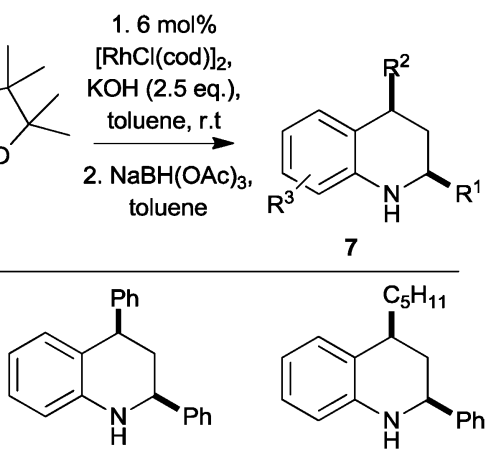

7c, $95 \%, d r>95:<5$<smiles>C[C@H]1C[C@H](c2ccccc2)c2ccccc2N1</smiles>

7i, $91 \%, d r>95:<5$<smiles>C[C@H]1C[C@H](c2ccccc2)c2ccc(C(F)(F)F)cc2N1</smiles>

7m, 73\%, dr 90:10

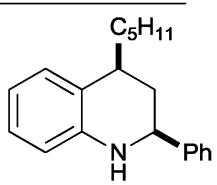

$\mathbf{7 g},{ }^{\text {a }} 76 \%, d r$ 95:5<smiles>CCCCCCCCCCCCC</smiles>

7j, $70 \%, d r 90: 10$

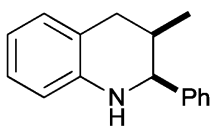

$9,{ }^{\mathrm{b}} 67 \%, d r>95:<5$
Scheme 2 Stereoselective synthesis of tetrahydroquinolines. Diastereomeric ratios (dr) for purified products. ${ }^{a}$ Performed at $50{ }^{\circ} \mathrm{C}$. ${ }^{b}$ Performed at $40{ }^{\circ} \mathrm{C}$ with 2-methyl-1-phenylprop-2-en-one; reduction conditions: $\mathrm{LiAlH}_{4}$, toluene, r.t. Ar" $=p$-chlorophenyl. were obtained in good yield and with high diastereoselectivity. The accessibility of substituted 2-aminophenyl pinacolboronates enabled the synthesis of tetrahydroquinolines $7 \mathbf{j}-\mathbf{m}$ in which the benzenoid ring had been substituted.

The syntheses of the 2,4-disubstituted tetrahydroquinolines 7 were all highly diastereoselective in favour of the cis diastereoisomer. The 1,3-diaxial orientations of $\mathrm{H}-2$ and $\mathrm{H}-4$ were determined by careful analysis of vicinal coupling constants ${ }^{13}$ and, for $\mathbf{3 h}$ and $\mathbf{3 l}$, observation of strong mutual nOe interactions; in addition, the cis diastereoisomer of $\mathbf{3 d}$ is a known compound. ${ }^{14}$ The stereoselectivity may be explained in terms of axial attack ${ }^{15}$ of the reducing agent on the 3,4-dihydroquinoline intermediate.

Extension to the synthesis of a 2,3-disubstituted tetrahydroquinoline was also possible (Scheme 2). Thus, with 2-methyl-1phenyl prop-2-en-one, the known $^{16}$ tetrahydroquinoline $\mathbf{9}$ $\left({ }^{3} \mathrm{H}_{\mathrm{H} 2 \mathrm{H} 3}=3.5 \mathrm{~Hz}\right)$ was obtained in $67 \%$ yield as a $>95:<5$ mixture of diastereoisomers. As previously observed with the $\beta$-unsubstituted enone $(\rightarrow \mathbf{7 b}$; compare Scheme 1 with Scheme 2$)$, the yield was higher with the pinacolboronate $8\left(\mathrm{R}^{3}=\mathrm{H}\right)$ as the reactant $(67 \%)$ than with the corresponding boronic acid 3 (58\%).

We next focused on the development of an asymmetric tetrahydroquinoline synthesis. In studies directed towards an asymmetric synthesis of tetrahydroquinolones, we had found that addition of the pinacolboronate $8\left(\mathrm{R}^{3}=\mathrm{H}\right)$ to methyl cinnamate gave racemic products with a wide range of chiral ligands; however, the corresponding Boc-protected substrate $10\left(\mathrm{R}^{3}=\mathrm{H}\right)$ gave, with $(R, R, S, S)$ Duanphos as ligand, ${ }^{17,18}$ a low yield of the corresponding tetrahydroquinolone in $>98 \%$ ee (ESI $\dagger$ ). These initial results prompted us to investigate the addition of the Boc-protected pinacolboronates $\mathbf{1 0}$ to unsaturated ketones. In each case, the intermediate conjugate addition products were treated with triethylsilane in TFA to effect deprotection, cyclisation and reduction, and the enantiomeric excess of the corresponding tetrahydroquinolines 8 was determined by chiral HPLC (Table 1 ).

The reactions of the Boc-protected pinacolboronate $\mathbf{1 0}$ $\left(\mathrm{R}^{3}=\mathrm{H}\right)$ with a range of $\alpha, \beta$-unsaturated ketones, catalysed by $6 \mathrm{~mol} \%(R, R, S, S)$-Duanphos[Rh(nbd)][ $\left.\mathrm{BF}_{4}\right]$, were successful with both aromatic and aliphatic $\mathrm{R}^{1}$ and $\mathrm{R}^{2}$ groups (entries $1-4$, Table 1 ). The use of the Boc-protected pinacolboronate $10\left(\mathrm{R}^{3}=\mathrm{CF}_{3}\right)$ was also successful, and allowed variation of the substitution of the benzenoid ring (entries 5-7). The stereoselectivity of the reactions was remarkable: the products 7 were obtained with very high cis diastereoselectivity and with good to excellent enantiomeric excess. The absolute configuration of the tetrahydroquinolines $\mathbf{7 c}$ and $\mathbf{7 l}$ was determined by comparison of their experimental and simulated vibrational circular dichroism spectra. ${ }^{19}$ This outcome is consistent with the observed sense of induction in reported asymmetric conjugate addition reactions using this catalyst system. ${ }^{18}$

We also investigated the effect of generating the chiral catalyst in situ. Thus, the enantiomerically-enriched tetrahydroquinolines ent-7c and $7 \mathbf{g}$ could be prepared using the combination of $3 \mathrm{~mol} \%[\mathrm{Rh}(\mathrm{nbd}) \mathrm{Cl}]_{2}$ and $6 \mathrm{~mol} \%$ of either $(S, S, R, R)$ or $(R, R, S, S)$-Duanphos (entries 8 and 9 , Table 1$)$. The yield of the tetrahydroquinoline 7c was higher under these conditions than with $6 \mathrm{~mol} \%(R, R, S, S)$-Duanphos[Rh(nbd)][ $\left.\mathrm{BF}_{4}\right]$ (compare entries 2 and 8 ). 
Table 1 Asymmetric synthesis of tetrahydroquinolines

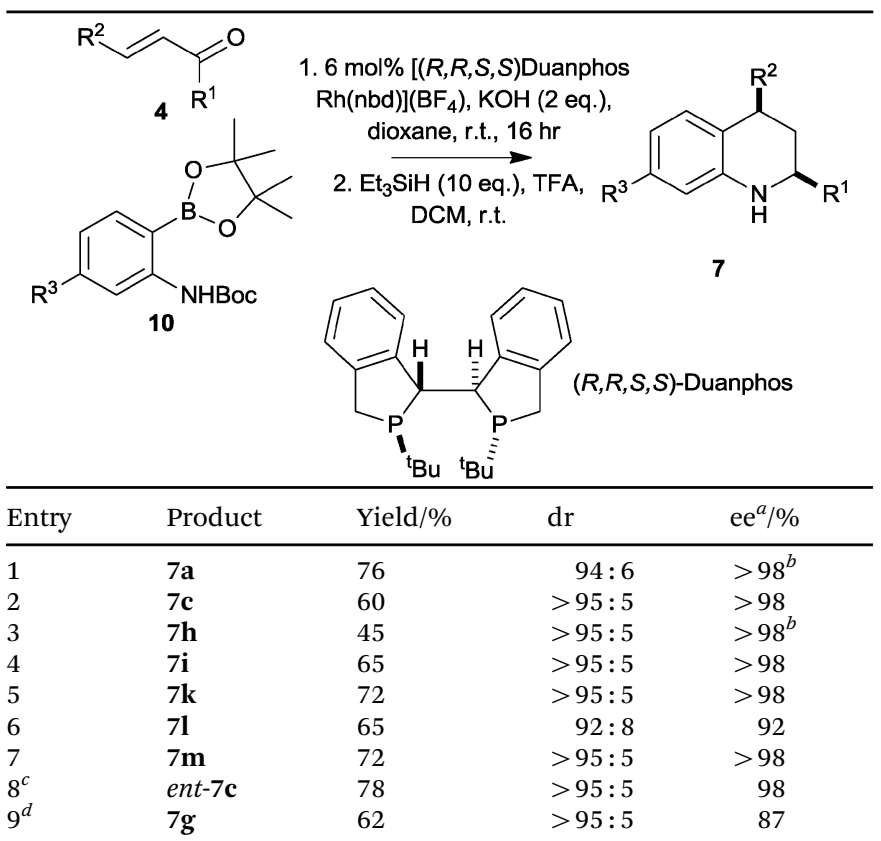

${ }^{a}$ Determined by chiral analytical HPLC. ${ }^{b}$ The ee of the corresponding 3,5-dinitrobenzamide derivative was determined. ${ }^{c} 3 \mathrm{~mol} \%[\mathrm{Rh}(\mathrm{nbd}) \mathrm{Cl}]_{2}$ and $6 \mathrm{~mol} \%(S, S, R, R)$-Duanphos were used. ${ }^{d} 3 \mathrm{~mol} \%[\mathrm{Rh}(\mathrm{nbd}) \mathrm{Cl}]_{2}$ and $6 \mathrm{~mol} \%(R, R, S, S)$-Duanphos were used.

A novel convergent and stereoselective synthesis of tetrahydroquinolines exploited the Rh-catalysed addition of 2-aminophenyl boronate derivatives to $\alpha, \beta$-unsaturated ketones as the key step. Remarkably, it was possible to develop a highly enantioselective variant of the reaction that exploited the specific combination of Duanphos as the chiral ligand and Boc-protected pinacolboronates as the reactants. The synthetic approach was modular, and will likely be adapted to synthesis of a range of other benzo-fused heterocyclic ring systems. We thank EPSRC and GlaxoSmithKline for funding, Douglas Minick for conducting VCD experiments, and Amgen and ChiralQuest for generous gifts of metal complexes.

\section{Notes and references}

\# See ref. $9 a$ for evidence for the formation of $5\left(\mathrm{R}^{1}=\mathrm{Me} ; \mathrm{R}^{2}=\mathrm{C}_{5} \mathrm{H}_{11}\right)$.

1 A. R. Katritzky, S. Rachwal and B. Rachwal, Tetrahedron, 1996, 52, 15031.

2 M. Konishi, H. Ohkuma, K. Matsumoto, T. Tsuno, H. Kamei, T. Miyaki, T. Oki, H. Kawaguchi, G. D. VanDuyne and J. Clardy, J. Antibiot., 1989, 42, 1449.

3 (a) L. R. Bush, Cardiovasc. Drug Rev., 1991, 9, 247; (b) S. Imanishi, T. Kimura and M. Arita, Cardiovasc. Drug Rev., 1991, 9, 223.

4 For examples, see: (a) W.-B. Wang, S.-M. Lu, P.-Y. Yang, X.-W. Han and Y.-G. Zhou, J. Am. Chem. Soc., 2003, 125, 10536; (b) M. T. Reetz and X. Li, Chem. Commun., 2006, 2159; (c) W.-J. Tang, S.-F. Zhu, L.-J. Xu, Q.-L. Zhou, Q.-H. Fan, H.-F. Zhou, K. Lam and A. S. C. Chan, Chem. Commun., 2007, 613; (d) C. Wang, C. Li, X. Wu, A. Pettman and J. Xiao, Angew. Chem., Int. Ed., 2009, 48, 6524; (e) T. Wang, L.-G. Zhuo, Z. Li, F. Chen, Z. Ding, Y. He, Q.-H. Fan, J. Xiang, Z.-X. Yu and A. S. C. Chan, J. Am. Chem. Soc., 2011, 133, 9878; $(f)$ H. Zhou, Z. Li, Z. Wang, T. Wang, L. Xu, Y. He, Q.-H. Fan, J. Pan, L. Gu and A. S. C. Chan, Angew. Chem., Int. Ed., 2008, 47, 8464.

5 (a) M. Rueping, A. P. Antonchick and T. Theissmann, Angew. Chem., Int. Ed., 2006, 45, 3683; (b) Q.-S. Guo, D.-M. Du and J. Xu, Angew. Chem., Int. Ed., 2008, 47, 759; (c) M. Rueping, T. Theissman, S. Raja and J. W. Bats, Adv. Synth. Catal., 2008, 350, 1001; (d) M. Rueping and T. Theissman, Chem. Sci., 2010, 1, 473; (e) M. Rueping, T. Theissman, M. Stoeckel and A. P. Antonchick, Org. Biomol. Chem., 2011, 9, 6844; $(f)$ Q. A. Chen, K. Gao, Y. Duan, Z. S. Ye, L. Shi, Y. Yang and Y.-G. Zhou, J. Am. Chem. Soc., 2012, 134, 2442; $(g)$ X.-F. Tu and L.-Z. Gong, Angew. Chem., Int. Ed., 2012, 51, 11346.

6 Z.-Y. Han, H. Xiao, X.-H. Chen and L.-Z. Gong, J. Am. Chem. Soc., 2009, 131, 9182.

7 (a) H. Ishitani and S. Kobayashi, Tetrahedron Lett., 1996, 37, 1973. For select recent examples, see: (b) T. Akiyama, H. Morita and K. Fuchibe, J. Am. Chem. Soc., 2006, 128, 13070; (c) H. Liu, G. Dagousset, G. Masson, P. Retailleau and J. Zhu, J. Am. Chem. Soc., 2009, 131, 4598; (d) G. Bergonzini, L. Gramigna, A. Mazzanti, M. Fochi, L. Bernardi and A. Ricci, Chem. Commun., 2010, 46, 327; (e) M.-S. Xie, X.-H. Chen, Y. Zhu, B. Gao, L.-L. Lin, X.-H. Liu and X.-M. Feng, Angew. Chem., Int. Ed., 2010, 49, 3799; $(f)$ H. Xu, S. J. Zuend, M. G. Woll, Y. Tao and E. N. Jacobsen, Science, 2010, 327, 986; $(g)$ G. Dagousset, J. P. Zhu and G. Masson, J. Am. Chem. Soc., 2011, 133, 14804; (h) C. Min, N. Mittal, D. X. Sun and D. Seidel, Angew. Chem., Int. Ed., 2013, 52, 14084; (i) C. S. Luo and Y. Huang, J. Am. Chem. Soc., 2013, 135, 8193; $(j)$ J. Calleja, A. B. GonzalezPerez, A. R. de Lera, R. Alvarez, F. J. Fananas and F. Rodriguez, Chem. Sci., 2014, 5, 996.

8 (a) S. Murarka, I. Deb, C. Zhang and D. Seidel, J. Am. Chem. Soc., 2009, 131, 13226; (b) K. Mori, K. Ehara, K. Kurihara and T. Akiyama, J. Am. Chem. Soc., 2011, 133, 6166; (c) Y.-K. Kang, S. M. Kim and D. Y. Kim, J. Am. Chem. Soc., 2010, 132, 11847.

9 (a) J. Horn, S. P. Marsden, A. Nelson, D. House and G. G. Weingarten, Org. Lett., 2008, 10, 4117; (b) J. Horn, H. Y. Li, S. P. Marsden, A. Nelson, R. J. Shearer, A. J. Campbell, D. House and G. G. Weingarten, Tetrahedron, 2009, 65, 9002; (c) P. Tosatti, J. Horn, A. J. Campbell, D. House, A. Nelson and S. P. Marsden, Adv. Synth. Catal., 2010, 352, 3153; (d) P. Tosatti, A. J. Campbell, D. House, A. Nelson and S. P. Marsden, J. Org. Chem., 2011, 76, 5495.

10 (a) M. Sakai, H. Hayashi and N. Miyaura, Organometallics, 1997, 16, 4229. For reviews, see: (b) T. Hayashi, Synlett, 2001, 879; (c) K. Fagnou and M. Lautens, Chem. Rev., 2003, 103, 169; (d) H. J. Edwards, J. D. Hargrave, S. D. Penrose and C. G. Frost, Chem. Soc. Rev., 2010, 39, 2093.

11 (a) Y. Takaya, M. Ogasawara, T. Hayashi, M. Sakai and N. Miyaura, J. Am. Chem. Soc., 1998, 120, 5579. For reviews, see ref. 10c,d and: (b) T. Hayashi and K. Yamasaki, Chem. Rev., 2003, 103, 2829; (c) D. Mueller and A. Alexakis, Chem. Commun., 2012, 48, 12037.

12 O. Baudoin, D. Guénard and F. Guéritte, J. Org. Chem., 2000, 65, 9268.

13 M. Karplus, J. Am. Chem. Soc., 1963, 85, 2870.

14 M. Ueda, S. Kawai, M. Hayashi, T. Naito and O. Miyata, J. Org. Chem., 2010, 75, 914.

15 R. V. Stevens, in Strategies and Tactics in Organic Synthesis, ed. T. Lindberg, Academic Press, 1984, vol. 1.

16 S.-I. Murahashi, Y. Imada and Y. Hirai, Bull. Chem. Soc. Jpn., 1989, 62, 2968.

17 (a) D. Liu and X. Zhang, Eur. J. Org. Chem., 2005, 646; (b) I. C. Lennon, Chim. Oggi, 2010, 28, 46.

18 For an example of a Rh-catalysed conjugate addition with Duanphos as ligand, see: J. L. Zigterman, J. C. S. Woo, S. D. Walker, J. S. Tedrow, C. J. Borths, E. E. Bunel and M. M. Faul, J. Org. Chem., 2007, 72, 8870.

19 (a) P. J. Stephens, in Computational Medicinal Chemistry for Drug Discovery, ed. P. Bultinick, H. de Winter, W. Langenaeker and J. P. Tollenare, Marcel Dekker, New York, 2004, pp. 699-725; (b) T. Kuppens, P. Bultinick and W. Langenaeker, Drug Discovery Today: Technol., 2004, 1, 269. 